\title{
Real-life effectiveness of montelukast administered as monotherapy or in combination with inhaled corticosteroid (ICS) in pediatric patients with uncontrolled asthma
}

\author{
Denis Bérubé ${ }^{1}$, Michel Djandji ${ }^{2}$, John S Sampalis ${ }^{3,4^{*}}$, Allan Becker ${ }^{5}$ \\ From Canadian Society of Allergy and Clinical Immunology Annual Scientific Meeting 2013 \\ Toronto, Canada. 3-6 October 2013
}

\section{Background}

The efficacy of montelukast in the treatment of asthma has been demonstrated in numerous controlled clinical trials. The aim of this study was to assess the real-life effectiveness of montelukast administered as monotherapy or in combination with current ICS in children with uncontrolled asthma.

\section{Methods}

Twelve-week open-label, phase IV, multicenter, prospective cohort study. Eligible patients included children aged 2-14 years diagnosed with asthma for $=6$ months who were: (i) uncontrolled as per the Canadian Asthma Consensus Guidelines, and; (ii) either untreated, using a short-acting $ß 2$-agonist as-needed or using any dose ICS. In this analysis, patients with Asthma Control Questionnaire (ACQ) score $>0.75$ were included. Patients 6-14 and 2-5.9 years old were treated once-daily with montelukast $5 \mathrm{mg}$ and $4 \mathrm{mg}$, respectively. Primary outcome measure was the proportion achieving asthma control $(\mathrm{ACQ}=0.75)$. Secondary outcomes were the absolute change in ACQ and in the Pediatric Asthma Caregiver's Quality of Life Questionnaire (PACQLQ) over time.

\section{Results}

Among the 328 patients included, 76 (23.2\%) were treated with montelukast monotherapy and 252 (76.8\%) with montelukast combined with ICS. By 4 weeks of treatment $61.3 \%$ and $52.9 \%$ of patients in the monotherapy and combination group, respectively, achieved asthma control.
These proportions increased to $75.0 \%$ and $70.9 \%$, respectively, at week-12. Clinically and statistically $(\mathrm{P}<0.001)$ significant improvements were observed in ACQ (monotherapy: mean (SD) of 1.67 (0.69) at baseline and $0.50(0.52)$ at week-12; combination therapy: 2.02 $(0.83)$ and $0.64(0.86)$, respectively) and PACQLQ (monotherapy: mean (SD) of 5.34 (1.14) at baseline and 6.51 (0.85) at week-12; combination therapy: $4.42(1.35)$ and 6.21 (1.03), respectively) in both patient subgroups. After a 12 -week montelukast add-on therapy, $22.6 \%$ of patients reduced their ICS dosage.

\section{Conclusions}

Montelukast as monotherapy or in combination with ICS represents an effective treatment strategy for achieving asthma control in pediatric patients and improving caregivers' quality of life.

\section{Acknowledgements}

On behalf of the $\mathrm{ACTION}^{3}$ investigators.

\section{Trial registration}

Clinicaltrials.gov: 00832455.

\section{Authors' details \\ ${ }^{1}$ Centre Hospitalier Universitaire (CHU) Sainte-Justine, Université de Montréal, Montréal, Québec, H7M 5M2, Canada. ${ }^{2}$ Merck Canada Inc., Kirkland, Québec, H9H 3L1, Canada. ${ }^{3}$ McGill University, Montréal, Québec, H3G 1Y6, Canada. ${ }^{4}$ JSS Medical Research, St-Laurent, Québec, H4S 1N8, Canada. ${ }^{5}$ Section of Allergy and Clinical Immunology, Department of Pediatrics and Child Health, University of Manitoba, Winnipeg, Manitoba, R3A 1S1, Canada.}


doi:10.1186/1710-1492-10-S1-A55

Cite this article as: Bérubé et al:: Real-life effectiveness of montelukast administered as monotherapy or in combination with inhaled

corticosteroid (ICS) in pediatric patients with uncontrolled asthma. Allergy, Asthma \& Clinical Immunology 2014 10(Suppl 1):A55.

Submit your next manuscript to BioMed Central and take full advantage of:

- Convenient online submission

- Thorough peer review

- No space constraints or color figure charges

- Immediate publication on acceptance

- Inclusion in PubMed, CAS, Scopus and Google Scholar

- Research which is freely available for redistribution

Submit your manuscript at www.biomedcentral.com/submit
C Biomed Central 